\title{
Analisis Peluang Usaha Wedding Organizer Pada Kaum Millennial
}

\author{
Rinita Sinaga ${ }^{1 *}$, Rizka Ramadhana Sembiring ${ }^{2}$ \\ ${ }^{12}$ Program Studi Pendidikan Luar Sekolah, Universitas Negeri Medan \\ Email : rinitasinaga02@gmail.com
}

\begin{abstract}
Abstrak
Pernikahan merupakan acara sakral dan suci hingga menuntut kelancaran. Bagi sebagian besar orang di Indonesia, untuk menyelenggarakan acara kecil-menengah mungkin masih bisa dengan bantuan tetangga dan kerabat. Namun, kini sangat terbuka celah pasar bagi pengusaha jasa WO dikarenakan perubahan budaya dan gaya hidup serta kemapanan finansial. Sekarang sudah banyak orang malu untuk meminta bantuan kerabat yang pastinya tidak punya banyak waktu. Ditambah lagi, serba instan dan praktis adalah ciri khas masyarakat modern. Lebih- lebih jika acaranya besar-besaran, mereka tidak akan memberikan tugas kepada sembarangan orang, butuh tenaga ahli dan berpengalaman yang disebut wedding organizer. Dengan adanya jasa WO yang profesional, mau acara sebesar apapun dengan tempo persiapan sesingkat- singkatnya pun bisa diatasi tanpa perlu menguras tenaga dan fikiran shohibul-bet. WO bertugas menyusun acara serapi mungkin dan sesuai selera keluarga dan mempelai. Mulai dari prawedding, pencarian tempat dan domisili tepat (gedung atau hotel), pengisi acara, ketering, dekorasi, hingga mengorganisasikan saat hari-H. seiring perkembangan zaman jasa weeding organizer banyak dibutuhkan oleh masyarakat yang ingin melaksanakan resepsi pernikahan. WO menjadi suatu usaha yang begitu menjanjikan. Untuk mengetahui bagaimana peluang usaha weeding organizer maka dari itu penulis jurnal ini.
\end{abstract}

Kata Kunci : pernikahan, wedding organizer, milleniial, bisnis

\section{Analysis of Wedding Organizer Business Opportunities for Millennials}

Marriage is a sacred and sacred event that demands smoothness. For most people in Indonesia, to hold a small-medium event may still be possible with the help of neighbors and relatives. However, now there is a very open market gap for WO service entrepreneurs due to changes in culture and lifestyle and financial security. Now many people are ashamed to ask for help from relatives who certainly do not have much time. Plus, being instant and practical is the hallmark of modern society. The more so if the event is large-scale, they will not give assignments to just anyone, need skilled and experienced staff called a wedding organizer. With the existence of a professional WO service, any event as big as possible with the shortest possible preparation time can be overcome without the need to drain the energy and thoughts of shohibul-bet. WO has the duty to arrange the event as neatly as possible and according to the taste of the family and the bride and groom. Starting from prawedding, finding the right place and domicile (building or hotel), performers, events, decoration, to organizing on D-day. along with the times the weeding organizer services are much needed by people who want to carry out wedding receptions. WO became a business that was so promising. To find out how weeding organizer business opportunities, therefore the author of this journal.

Keywords: wedding, wedding organizer, millennial, business 


\section{Journal of Millennial Community, 3 (2), September 2021}

Rinita Sinaga, Rizka Ramadhana Sembiring

\section{PENDAHULUAN}

\section{Akibat kebutuhan yang banyak dalam menyelenggarakan pesta pernikahan namun kurangnya koordinasi sering kali menjadi pemicu hambatan dalam terlaksananya acara.}

Sehingga tak jarang bila kita menemukan pesta pernikahan tanpa persiapan yang matang. Oleh karna itu dengan adanya Wedding Organizer merupakan sebagai salah satu upaya dalam membantu menyiapkan pesta pernikahan. Menjadi seorang perencana pernikahan atau Wedding Organizer berarti menjadi "Troubleshooter" di setiap pernikahan yang dikerjakan.

Pernikahan adalah momen paling penting bagi pasangan pengantin, peristiwa yang diharapkan terjadi sekali seumur hidup ini tentu memerlukan persiapan yang sangat matang. Karena itu lah peluang bisnis Wedding Organizer sangat menjanjikan, ada pila WO yang menyesuaikan budge konsumen (biaya) dan menyesuaikan apa yang diinginkan konsumen.

Menggunakan jasa WO tidak semata-mata dengan alasan ingin bebas dari segala kerepotan yang akan dihadapi dalam menyiapkan pesta pernikahan. Idealnya biaya yang dikeluarkan untuk menyewa jasa Wedding Organizer harus berbalas setimpal atau bahkan lebih memuaskan. Karena profesionalitas seorang WO dipertaruhkan nantinya ketika berhasil atau tidaknya sebuah acara.

Wedding Organizera dalah suatu jasa yang memberikan pelayanan khusus secara pribadiyang bertujuan untukmembantu calon pengantin dan keluarga calon pengantin dari mulai perencanaan (planning) sampai tahap pelaksanaan.

Organizermemberikan mengenai berbagai macam hal yang berhubungan dengan acara pernikahan danmembantu merumuskan segala hal yang dibutuhkan pada saat pernikahan. Wedding Organizermemberikan solusi mulai dari tata rias, dekorasi, pre wedding, gedung, catringdan segala sesuatu yang dibutuhkan pada saat acara pernikahan berlangsung.

Seiring dengan zaman yang semakin modern dan menuntut masyarakat untuk menjadi lebih sibuk bekerja, wedding organizer menjadi sebuah solusibagi para pasangan yang bekerja dalam mempersiapkan pernikahannya. Secara umum dengan perkembangan budaya saat ini kebanyakan masyarakat luas menginginakan sebuah perniakahan atau pesta yang modern seperti pernikahan-pernikahan yang ada di Manca Negara, sudah banyak masyarakat Indonesia sekarang yang menggunakan konsep pernikahan atau pesta modern dari pada pernikahan yang tradisional. Sektor industry jasa memiliki peluang yang berpotensi membantu pertumbuhan ekonomi Indonesia sebesar 14,7 \% (Kartika, 2017).

\section{METODE}

Pada penelitian ini penulis menggunakan metode deskriptif, yaitu metode yang menggambarkan suatu keadaan ataupermasalahan yang sedang terjadi berdasarkan fakta dan data-data yang diperoleh dan dikumpulkan pada waktu melaksanakan penelitian. Yang dilakukan penulis yaitu berupa studi pustaka. Studi pustaka merupakan Pengumpulan data dengan cara mengumpulkan bacaanbacaanyang ada kaitannyadengan judul penelitinan. Dalam penyusunan kajian pustaka ini melakukan identifikasi secara sistematis, penemuan, dan analisis dokumen 
dokumen yang memuat atau berhubungan dengan masalah dalam penelitian yang anda lakukan. Triyono mengatakan bahwa kajian pustaka mencakup uraian mengenai kajian literatur yang menimbulkan gagasan untuk menyusun kerangka pemecahan masalah.

\section{HASIL DAN PEMBAHASAN}

Beberapa tahun lalu, istilah wedding organizer mungkin masih terdengar asing di telinga. Kebanyakan calon pengantin masih mempersiapkan pernikahan sendiri dengan bantuan keluarga atau teman-teman terdekat. Tak jarang pula orang yang mempertanyakan apakah wedding planner atau wedding organizer itu?

Namun akhir-akhir ini jarang sekali calon pengantin yang menggunakan jasa wedding organizer dalam mempersiapkan pernikahan mereka. Hal ini biasanya disebabkan kesibukan para calon pengantin yang umumnya bekerja, begitupun keluarga atau kerabat. Bahkan, dengan begitu banyak hal yang harus dikerjakan sepanjang persiapan, tak jarang pada akhirnya terjalin kedekatan antara wedding organizer dengan calon pengantin bahkan dengan kedua belah pihak keluarga. Tugas wedding organizer pun meluas menjadi pihak yang bertanggung jawab atas kelancaran jalannya sebuah pesta pernikahan dari mulai akad nikah atau pemberkatan hingga resepsi pernikahan. Ingin tahu lebih banyak mengenai peran wedding organizer, simak ulasan di bawah ini.

Wedding Organizer adalah suatu jasa khusus yang secara pribadi membantu calon pengantin dan keluarga dalam perencanaan dan supervisi pelaksanaan rangkaian acara pesta pernikahan sesuai dengan jadwal yang telah ditetapkan.
Wedding Organizer memberikan informasi mengenai berbagai macam hal yang berhubungan dengan acara pernikahan, membantu merumuskan konsep pernikahan. Wedding Organizer memfasilitasi, negosiasi dan koordinasi Page|109 dengan pihak gedung/hotel dan supplier/vendor seperti : Catering, dekorasi, fotografer, perias, grup musik, dan lain-lain.

Wedding Organizer membantu memilih jenis makanan dan food tasting. Menghubungi setiap rekan untuk follow up yang diperlukan, mengikuti rapat koordinasi dengan keluarga, juga memimpin rapat teknis dengan para rekanan. Technical meeting di tempat resepsi. Membantu menyusun buku acara dan lain-lain yang berhubungan dengan acara pernikahan.

\section{Peran Wedding Organizer}

1. Meringankan Beban Calon Mempelai Menggunakan jasa wedding organizer memang bukan sebuah keharusan, akan tetapi seiring perkembangan zaman, jasa wedding organizer semakin dibutuhkan karena dapat meringankan beban calon mempelai. Beberapa tugas wajib wedding organizer adalah :

a. Sebagai perencana, yaitu memberi usulan dan masukan tentang konsep acara, biaya, venue, vendor-vendor seperti dekorasi, katering, foto dan video, multi- media, MC, dan lainnya sesuai dengan kebutuhan dan keinginan calon pengantin.

b. Sebagai koordinator, yaitu mengkoordinasi seluruh pihak yang terlibat di pesta pernikahan, mulai dari calon mempelai, keluarga, para vendor dan pengisi acara, termasuk pengaturan jadwal technical meeting, dan gladi bersih. 


\section{Journal of Millennial Community, 3 (2), September 2021 \\ Rinita Sinaga, Rizka Ramadhana Sembiring}

c. Membuat rundown acara secara keseluruhan dan membentuk tim professional untuk mengatur jalannya pesta pernikahan mulai dari persiapan, gladi bersih, sampai acara selesai.

2. Menjadi Penengah dan Pemersatu Keluarga Calon Pengantin

Meski sudah ditangani oleh wedding planner atau wedding organizer professional, biasanya tetap ada panitia yang dibentuk dari keluarga calon pengantin. Karena tidak berpengalaman mengurus pesta pernikahan, panita keluarga ini kerap kurang mengerti apa yang harus mereka lakukan. Menjadi tugas wedding organizer untuk mengelola panita keluarga ini agar tidak perlu terjadi kesalahan yang tidak diinginkan. Perbedaan pendapat antara kedua pihak keluarga dalam sebuah pernikahan pun kerap terjadi. Terutama bila salah satu pihak memiliki posisi atau jabatan yang lebih tinggi daripada yang lain, dan pihak tersebut mengeluarkan uang lebih besar pula untuk membiayai pesta pernikahan.

Untuk hal-hal seperti ini, tugas seorang wedding organizer untuk menjadi penengah dan pemersatu bagi kedua keluarga. Tidak mudah memang. Namun, wedding planner dan wedding organizer berpengalaman biasanya memiliki kiat khusus menghadapi hal-hal seperti ini. Salah satunya dalah dengan menjadikan wedding organizer sebagai teman atau sahabat calon pengantin, dan bukan sebagai bawahan. Jelaskan kepada pihak keluarga bahwa wedding organizer lebih memahami seluk beluk pernikahan. Minta wedding organizer menjelaskan kepada kedua pihak keluarga hal-hal penting dalam sebuah prosesi pernikahan. Dengan cara yang bersahabat tentunya dan jangan berkesan menggurui. Biasanya, dengan kesabaran dan pengertian yang diberikan pihak keluarga akan mengerti dan pada akhirnya ditemukan titik temu yang memuaskan kedua belah pihak.

\section{Mengurangi Biaya Yang Tak Perlu}

Sebagai orang yang telah menangani beberapa pesta pernikahan, pada umunya wedding organizer mengerti bagaimana cara membantu calon pengantin menghemat pengeluaran. Untuk penghitungan makanan misalnya, setiap hotel, gedung, restoran dan katering memiliki porsi makanan yang berbeda- beda untuk satu orang tamu. Oleh karenanya, porsi makanan yang disajikan sebaiknya diperhitungkan dengan tepat, tidak kurang dan juga tidak berlebih, agar calon pengantin tenang, para tamu undangan pun nyaman. Calon pengantin pun harus jujur kepada wedding organizer mengenai besaran bujet yang telah mereka persiapkan.

\section{Usaha Wedding Organizer}

Dalam WO, konsep adalah raja. Jika konsep mewah, maka biaya mahal. Begitupun sebaliknya. Maka buatlah konsep yang sedetail mungkin hingga tidak akan rugi, dan tentunya tawarkanlah pelanggan kita dengan opsi lengkap, detail, best kwality, dan dengan variasi harga yang cukup beragam sebagai bahan pertimbangan pelanggan.

Hal mendasar yang dibutuhkan dalam usaha wedding organizer adalah kemampuan mengorganisasi, melakukan perencanaan, dan mengelola SDM. Kita hanya perlu modal konsep dan koneksi agar bisa menjalankan semua usaha ini. Jika EO mayotitas bisa berjalan diperkotaan saja, maka WO ini lebih mudah masuk kesemua daerah. Bedanya, di desa bisa dengan konsep banyak pernak-pernik tapi standar, diperkotaan meski lebih menyukai yang simple tapi juga harus terkesan mewah hingga daya kreativitas kita harus lebih menonjol. 


\section{Bisnis Wedding Organizer Yang Semakin Menjanjikan}

Berangkat dari dibutuhkannya peranan Wedding Organizer untuk membantu menyelenggarakan acara pernikahan agar berjalan dengan baik itulah, maka peluang bisnis ini akan semakin menjanjikan kedepan.

Pesatnya pertumbuhan penduduk akan selalu menyediakan ladang untuk menghasilkan keuntungan, ditambah juga dengan semakin majunya perekonomian masyarakat kita juga akan membuat mereka tidak segan untuk menyewa jasa WO terutamanya bagi kalangan menengah keatas. Apalagi konon kabarnya keuntungan yang bisa di dapatkan dari usaha wedding organizer ini nilainya bisa cukup besar didapatkan. Rata-rata pelaku usahanya akan memberikan keleluasaan menentukan prihal budget yang di miliki kliennya untuk menyelanggarakan acara pernikahan, dan pihak wedding organizer akan menentukan biaya jasanya tersendiri, ada yang mematok semisal 10 atau 20 juta untuk setiap acara, atau ada juga yang memberlakukan sistim persentase dari budget yang di keluarkan seluruhnya.

Menariknya, keuntungan yang bisa di hasilkan dari bisnis wedding organizer yang cukup besar tersebut, bisa didapatkan dengan modal yang minim atau bahkan tanpa modal sama sekali. Mengapa bisa demikian? karena sudah menjadi lumrah, untuk bisa menyewa jasanya setiap klien akan di bebankan sejumlah biaya DP atau uang muka dari nilai keseluruhan, sehingga biaya tersebutlah yang di gunakan para wedding organizer untuk digunakan sebagai modal penyelenggaraan acara.

\section{Kepercayaan Modal Utama Yang Harus Dimiliki}

Untuk bisa menjalankan usaha wedding organizer ini dengan baik dan lancar, modal utama yang harus dimiliki bukanlah berupa uang, namun paling Page|111 pentingnya adalah kepercayaan dari calon konsumennya. Tidak seperti uang yang bisa dikatakan lebih mudah untuk diupayakan, kepercayaan dari konsumen ini akan cukup sulit didapatkan dalam waktu singkat, melainkan kita harus berusaha menumbuhkannya sedikit demi sedikit hingga bisa memiliki reputasi yang dipercaya. Hingga jika kita beruntung sudah memiliki reputasi yang baik di mata klien pun, masih perlu perjuangan untuk mempertahannya.

Maka jika kita serius ingin terjun menjalani bisnis wedding organizer ini perlu di jalankan secara bertahap mulai dari kecil menangani acara-acara pernikahan berskala sederhana terlebih dahulu sambil memupuk pengalaman sekaligus membangun reputasi yang baik agar bisa menjaring klien yang lebih besar kedepannya. Selain itu kita pun di haruskan pandai membangun jaringan dengan bidang usaha lain yang akan dilibatkan untuk keberlangsungan acara pernikahan seperti dengan para pebisnis catering, penyedia dekorasi, jasa fotografi, ahli make up, usaha souvenir pernikahan dan lain sebagainya.

Jika kita bisa serius membangun dan merintis usaha wedding organizer ini hingga berhasil memiliki reputasi yang baik, maka akan secara otomatis dapat menarik calon klien dengan sendirinya, dan tentu saja keuntungan yang besar pun akan dapat di raih dengan mudah.

Adapun kelebihan dalam menjalankan bisnis weeding organizer:

1. Modal relatif kecil

Dalam menjalankan bisnis weeding organizer modal yang didapat bisa 


\section{Journal of Millennial Community, 3 (2), September 2021 \\ Rinita Sinaga, Rizka Ramadhana Sembiring}

melalui uang panjar dari pelanggan. untuk memulai usaha ini yang terpenting adalang menjalin kerjasama dengan para vendor yang berkualitas dan pinter cari calon klien. sedangkan untuk peralatan yang dibutuhkan hanya kebutuhan administrasi awal usaha diantaranya telepon, kop surat. brosur, dan kartu nama hingga biaya promosi lewat website.

Persaingan usaha ini paling ketat berada dikelas menengah ke atas karena kalangan ini sering menggunakan jasa Wedding Organizer. Karena itu pelaku usaha yang targetnya kelas menegah ke atas berlomba-lomba memberikan sesuatu yang lebih dalam memenuhi kebutuhan klien.

\section{Membantu berfikir lebih kreatif}

Kreativitas adalah kemampuan seseorang untuk melahirkan sesuatu yang baru, baik berupa gagasan maupun karya nyata yang relative berbeda dengan apa yang telah ada sebelumnya, dalam menjalankan bisnis weeding organizer, seorang harus berfikir secara kreatif bagaimana mengkreasikan dan menata ruangan, pelaminan semenarik mungkin

3. Hasil yang didapatkan relatif besar Perusahaan jasa memang memiliki

modal relatif kecil dan menghasilkan pendapatan yang dikatakan relatif besar, tetapi hal itu harus sesuai dengan kerja kita karena semakin baik kerja kita maka semakin meningkat pula pendapatan seseorang. Seperti halnya tingginya tingkat kreativitas maka semakin tinggi pula penghasilan yang didapat.

4. Mendapatkan hal-hal baru dan menarik

Dalam menjalankan bisnis weeding organizer, kadang-kadang seseorang menemukan hal-hal baru dan hal-hal menarik. Misalnya dapat menemukan ide-ide aru, mendapatkan gagasan baru. Bisa jadi orang tersebut belum penah melakukan sesuatu dan mencoba sesuatu, tetapi setelah menjalankan bisnis weeding organizer ia baru merasakan hal tersebut.

\section{SIMPULAN}

Page | 112

Wedding Organizer memberikan informasi mengenai berbagai macam hal yang berhubungan dengan acara pernikahan, membantu merumuskan konsep pernikahan. Wedding Organizer memfasilitasi, negosiasi dan koordinasi dengan pihak gedung/hotel dan supplier/vendor seperti catering, dekorasi, fotografer, perias, grup musik, dan lain-lain. Adapun peran wedding organizer yaitu meringankan beban calon mempelai, menjadi penengah dan pemersatu keluarga calon pengantin, dan mengurangi biaya yang tak perlu. Kelebihan dalam menjalankan bisnis Wedding Organizer modal relatif kecil bahkan tidak menggunakan modal, membantu berfikir lebih kreatif, hasil yang didapatkan relatif besar, mendapatkan hal-hal baru dan menarik.

\section{DAFTAR PUSTAKA}

Ferdiansyah, F. (2016). Pengembangan bisnis tgif organizer Dalam meningkatkanmarket share. Jurnal Bisnis dan Manajemen, 52(11).

Melati, I. (2010). Segmentasi Pelanggan pada Bisnis Wedding Organizer. Binus Business Review, 1(2), 568-574.

Rugaya, S., \& Sudirman, M. (2016). Efektifitas Pelaksanaan Kursus Calon Pengantin (Studi Pada Kantor Urusan Agama Kecamatan Biringkanaya Kota Makassar). Jurnal Tomalebbi, (4), 157-168.

Samoedra, A. D. A., \& Ichsani, S. (2012, September). Berkembangnya Jasa Wedding Planner Sebagai Salah Satu Pengembangan Ekonomi Kreatif di Kota Bandung. Seminar Nasional Kewirausahaan dan Inovasi Bisnis II, Universitas Tarumanagara. 
Journal of Millennial Community, 3 (2), September 2021

Rinita Sinaga, Rizka Ramadhana Sembiring

\section{PROFIL SINGKAT}

Penulis merupakan mahasiswa program studi Pendidikan masyarakat. Rinita Sinaga, lahir di Lumban Malau, 03 Februari 1999, saat ini sedang menempuh pendidikan Sarjana Pendidikan Masyarakat di Universitas Negeri Medan. (2) Rizka Ramadhana S, lahir di Stabat, o2 Januari 200o, saat ini sedang menempuh studi akhir pendidikan Sarjana Pendidikan Masyarakat di Universitas Negeri Medan 